\title{
Doping technologies for InP membranes on silicon for nanolasers
}

\author{
Marchevsky, Andrey; Mørk, Jesper; Yvind, Kresten
}

\section{Published in:}

Proceedings of SPIE

Link to article, DOI:

$10.1117 / 12.2509487$

Publication date:

2019

Document Version

Publisher's PDF, also known as Version of record

Link back to DTU Orbit

Citation (APA):

Marchevsky, A., Mørk, J., \& Yvind, K. (2019). Doping technologies for InP membranes on silicon for nanolasers. In A. A. Belyanin, \& P. M. Smowton (Eds.), Proceedings of SPIE (Vol. 10939). [109390U] SPIE - International Society for Optical Engineering. Proceedings of SPIE - The International Society for Optical Engineering Vol. 10939 https://doi.org/10.1117/12.2509487

\section{General rights}

Copyright and moral rights for the publications made accessible in the public portal are retained by the authors and/or other copyright owners and it is a condition of accessing publications that users recognise and abide by the legal requirements associated with these rights.

- Users may download and print one copy of any publication from the public portal for the purpose of private study or research.

- You may not further distribute the material or use it for any profit-making activity or commercial gain

- You may freely distribute the URL identifying the publication in the public portal 


\section{Doping technologies for InP membranes on silicon for nanolasers}

\section{Andrey Marchevsky, Jesper Mørk, Kresten Yvind}

Andrey Marchevsky, Jesper Mørk, Kresten Yvind, "Doping technologies for InP membranes on silicon for nanolasers," Proc. SPIE 10939, Novel In-Plane Semiconductor Lasers XVIII, $109390 \mathrm{U}$ (1 March 2019); doi: 10.1117/12.2509487

SPIE. Event: SPIE OPTO, 2019, San Francisco, California, United States 


\title{
Doping technologies for InP membranes on silicon for nanolasers
}

\author{
Andrey Marchevsky*, Jesper Mørk, and Kresten Yvind \\ DTU Fotonik, Technical University of Denmark, Kgs. Lyngby, Denmark
}

\begin{abstract}
We present a systematic study of $\mathrm{Zn}$ thermal diffusion and $\mathrm{Si}$ ion implantation with subsequent rapid thermal annealing as the methods to fabricate lateral p-i-n junctions in InP membranes on silicon for use in electrically pumped in-plane nanolasers. We describe in detail optimized fabrication steps, which include MOVPE growth of InGaAs/InP epilayers, 2" InP to 4" $\mathrm{SiO}_{2} / \mathrm{Si}$ direct bonding, and several cycles of DUV lithography. Values for sheet resistance of p-InGaAs/InP and $\mathrm{n}$-InP membranes are obtained, which correspond to carrier concentration levels higher than $10^{18} \mathrm{~cm}^{-3}$ for both $\mathrm{Zn}$ diffused p-InP and Si-implanted n-InP.
\end{abstract}

Keywords: InP membrane, Si ion implantation, Zn diffusion, doping, III-V on silicon, wafer bonding

\section{INTRODUCTION}

Nowadays on-chip electrical interconnects use more than a half of the total processer power consumption and the power fraction used for communication increases for each technology node. The power consumption can be significantly reduced if on-chip electrical links are replaced by the optical links ${ }^{1}$. To implement optical on-chip interconnects, a crucial component is an electrically driven nanolaser. A good candidate for that is photonic crystal (PhC) InP-based nanolaser. There are two different approaches to electrical injection: vertical injection ${ }^{2}$ and lateral ${ }^{3,4,5}$. Following recent demonstrations ${ }^{6}$, design with the lateral electrical injection is the most promising. In this work, we investigate and optimize $\mathrm{Zn}$ thermal diffusion in MOVPE reactor and $\mathrm{Si}$ ion implantation with subsequent rapid thermal annealing as the methods to fabricate lateral p-i-n junction in InP membrane. All processing is done on a silicon substrate to be compatible with silicon photonics fabrication infrastructure.

\section{FABRICATION OVERVIEW}

The fabrication process starts with 2" InP substrates, on which we grow epitaxial layers of lattice-matched $\mathrm{In}_{0.53} \mathrm{Ga}_{0.47} \mathrm{As}$ (InGaAs) and InP by means of metal organic vapor phase epitaxy (MOVPE) (Fig. 1a). These layers are designed to have only intrinsic carrier concentration and are not intentionally doped. Then the 2" InP wafer is directly bonded to a 4" silicon wafer with $1.3 \mu \mathrm{m}$ of thermally grown $\mathrm{SiO}_{2}$ on top (Fig. 1b). The 4" Si wafer size is needed to be able to process sample with deep ultraviolet (DUV) lithography due to limitations of the DUV stepper.

Direct bonding includes the following steps. First, a thin $(3 \mathrm{~nm})$ layer of $\mathrm{Al}_{2} \mathrm{O}_{3}$ is deposited on both $\mathrm{InP}$ and $\mathrm{Si}$ wafers by atomic layer deposition (ALD). Second, wafers are gently pressed against each other at room temperature in order to be pre-bonded. Third, they are annealed at $300^{\circ} \mathrm{C}$ for 1 hour to increase the bond strength ${ }^{7} \cdot \mathrm{Al}_{2} \mathrm{O}_{3}$ is chosen as an intermediate layer because it is characterized by large density of $-\mathrm{OH}$ groups ${ }^{8}$, which attribute to high bonding strength.

Once bonded, the InP substrate is etched away by $\mathrm{HCl}$. InGaAs and InP etch stop layers are etched by $1 \mathrm{H}_{2} \mathrm{SO}_{4}: 8 \mathrm{H}_{2} \mathrm{O}_{2}: 8 \mathrm{H}_{2} \mathrm{O}$ and $1 \mathrm{HCl}: 4 \mathrm{H}_{3} \mathrm{PO}_{4}$, respectively, leaving a membrane consisting of $50 \mathrm{~nm}$ InGaAs and $250 \mathrm{~nm} \mathrm{InP}$ bonded to $\mathrm{SiO}_{2} / \mathrm{Si}$ substrate (Fig. 1c). After alignment marks defining using DUV lithography and InGaAs/InP/SiO 2 dry etching, the next steps are $\mathrm{Si}$ ion implantation and $\mathrm{Zn}$ thermal diffusion (Fig. 1d). These steps are described in detail in the

${ }^{*}$ Further author information:

A.Marchevsky: e-mail: andrma@fotonik.dtu.dk

Novel In-Plane Semiconductor Lasers XVIII, edited by Alexey A. Belyanin,

Peter M. Smowton, Proc. of SPIE Vol. 10939, 109390U - (C) 2019 SPIE

CCC code: $0277-786 \mathrm{X} / 19 / \$ 18 \cdot$ doi: $10.1117 / 12.2509487$

Proc. of SPIE Vol. $10939109390 U-1$ 
following sections. Then trenches in InGaAs/InP membrane are etched using reactive ion etching (RIE) with $\mathrm{CH}_{4} / \mathrm{H}_{2}$ chemistry (Fig. 1e). The role of trenches is to confine current in the designed areas. Next, InGaAs layer is wet etched everywhere except areas designed for "P" metal contacts (Fig. 1f). InGaAs is used as an intermediate layer between p-InP and "P" metal contacts due to poor performance of metal contacts directly to p-InP. Finally, "P" metal contacts (TilPt\Au) (Fig. 1g) and "N" metal contacts (NilGe\Au) (Fig. 1h) are fabricated on p-InGaAs/p-InP and n-InP, respectively, by using the lift-off technique. Sample is then rapid thermal annealed at $430^{\circ} \mathrm{C}$ to alloy n-contact and improve p-contact resistivity.

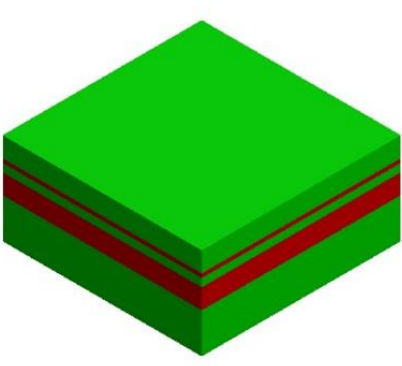

(a) MOVPE growth

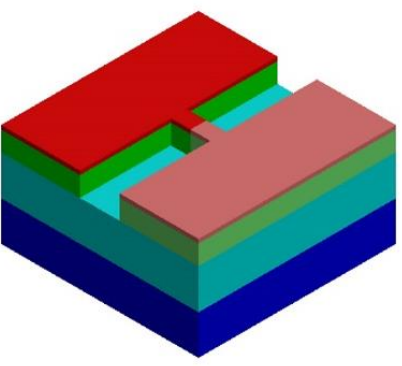

(e) Trenches dry etch

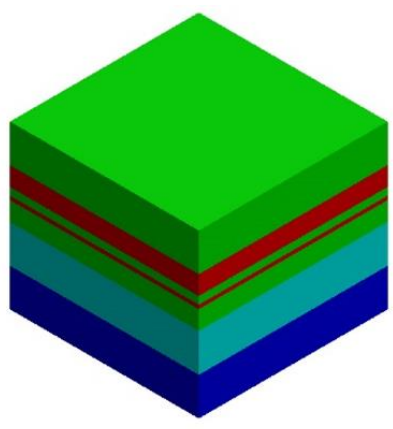

(b) Bonding to $\mathrm{SiO}_{2} / \mathrm{Si}$ wafer

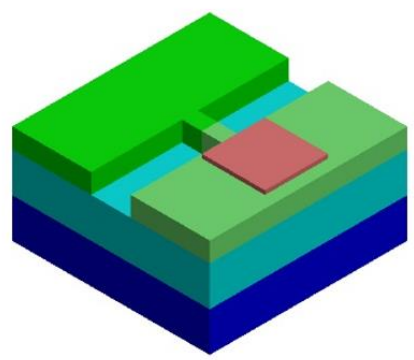

(f) InGaAs wet etch

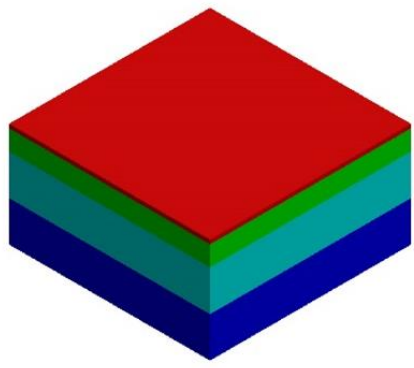

(c) InP substrate removal

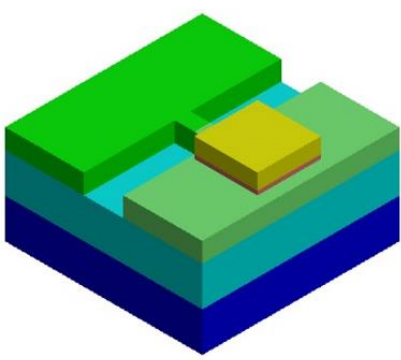

(g) "P" metal contacts deposition

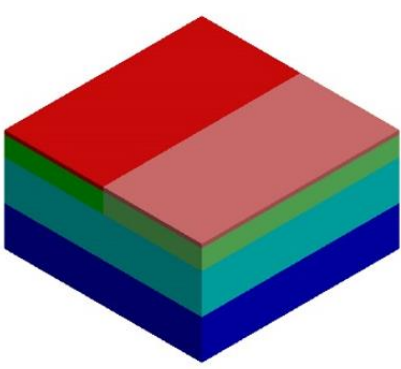

(d) Si ion implantation and $\mathrm{Zn}$ thermal diffusion

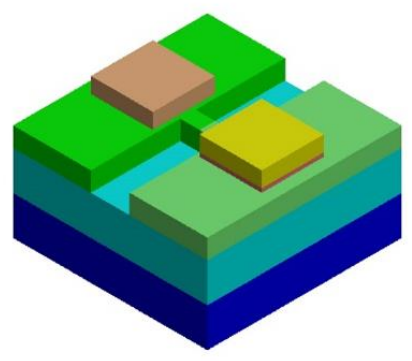

(h) "N" metal contacts deposition

Figure 1. Schematic view of the fabrication process.

\section{SI ION IMPLANTATION}

Ion implantation is a robust way for selective doping of semiconductor layers as it gives the possibility of good control over doping profile and doping level. Several types of dopants can be used for n-type doping of InP: examples are Group IV $(\mathrm{Si}, \mathrm{Ge}, \mathrm{Sn})$ and Group VI elements $(\mathrm{S}, \mathrm{Se}, \mathrm{Te})^{9}$. The best results can be achieved using $\mathrm{Si}$ as it introduces the least amount of lattice damage and does not redistribute to a large extent during subsequent high temperature annealing. However, lattice damage introduced by Si ion implantation can still be significant ${ }^{10,11}$, with the most damage located in the surface layer. For that reason, we perform $\mathrm{Si}$ ion implantation in the InGaAs/InP membrane with InGaAs on top, which is subsequently wet etched during the following processing.

To determine the important parameters of Si ion implantation, such as optimal energy of ions and minimal resist thickness, which is enough to block all $\mathrm{Si}^{+}$ions, simulation of $\mathrm{Si}$ ion implantation using Stopping Range of Ions in Matter (SRIM) software is carried out (Fig. 2). Optimal ion energy is found to be $180 \mathrm{keV}$ and minimal resist thickness $700 \mathrm{~nm}$. Dose is varied between $2 \cdot 10^{13} \mathrm{~cm}^{-2}$ and $2 \cdot 10^{14} \mathrm{~cm}^{-2}$, which correspond to $6.7 \cdot 10^{17} \mathrm{~cm}^{-3}-6.7 \cdot 10^{18} \mathrm{~cm}^{-3} \mathrm{Si}$ concentration in InP. Sample tilt is $7^{\circ}$ to prevent channeling effects, implantation is conducted at room temperature.

To be able to pattern structures for ion implantation with the size of critical dimension down to $300 \mathrm{~nm}$, we use DUV lithography. Thickness of bottom anti-reflective coating (BARC) is fixed to be $65 \mathrm{~nm}$, thickness of DUV resist is chosen to be $750 \mathrm{~nm}$. 

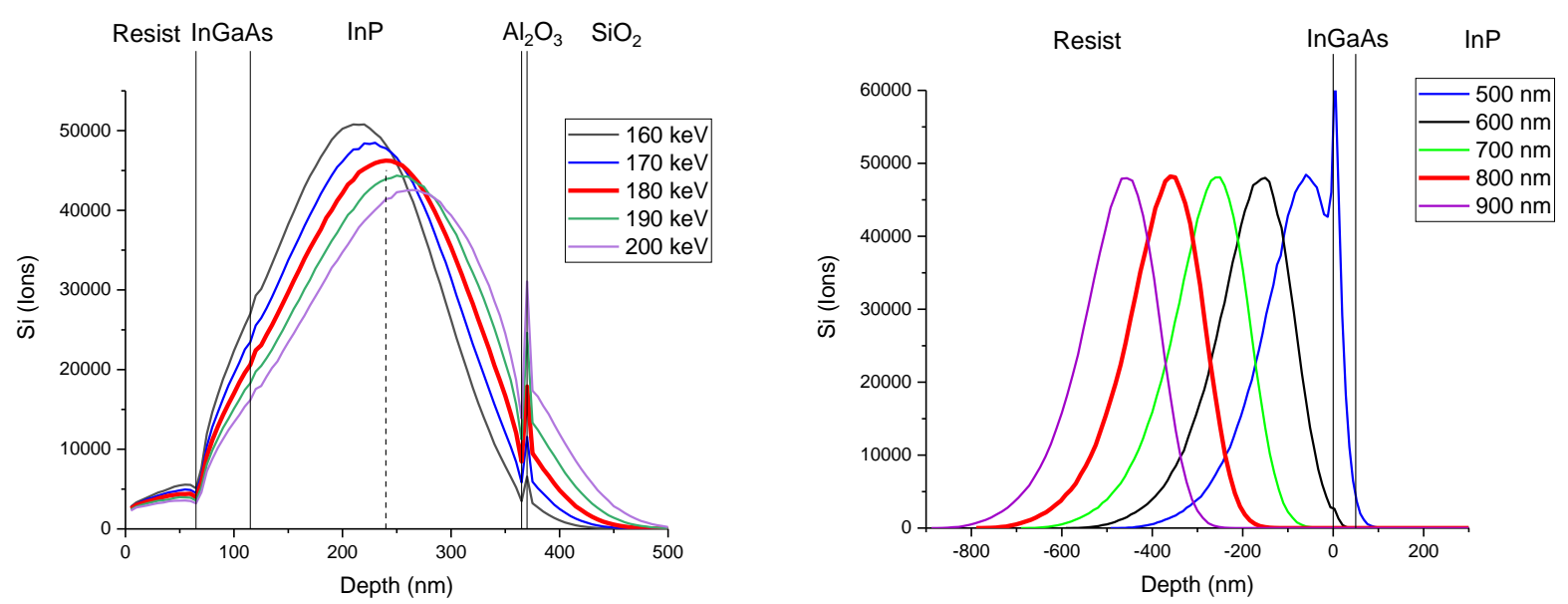

Figure 2. Results of Si ion implantation using SRIM software. Left: variation of Si ion energy. Right: variation of DUV resist thickness with fixed ion energy $(180 \mathrm{keV})$.

After ion implantation Si impurities need to be electrically activated. Activation is done by rapid thermal annealing at $800^{\circ} \mathrm{C}$ for $30 \mathrm{~s}$. Since InGaAs/InP can't withstand that high temperature, we need to protect it with deposition of a cap layer. $\mathrm{SiN}_{\mathrm{x}}$ and $\mathrm{SiO}_{2}$ cap layers turned out to be the bad choices: the InGaAs/InP membrane deteriorated a lot after annealing. Eventually, boron phosphorus silicate glass (BPSG) was found to be able to protect InGaAs/InP during annealing. We attribute that to BPSG's ability to reflow at high temperatures, which leads to reducing stress.

Electrical characterization of Si implanted $\mathrm{n}$-InP is done by transmission line measurement (TLM) of specially designed test structures: "N" metal contacts with different distances between them. By measuring resistance between different pairs of contacts, we can get information about sheet resistance $R_{S}$ and contact resistance $R_{C}$ by extrapolating data with the formula

$$
\mathrm{R}=\mathrm{R}_{\mathrm{S}} \cdot \frac{\mathrm{L}}{\mathrm{W}}+2 \mathrm{R}_{\mathrm{C}}
$$

where $\mathrm{R}$ is resistance between two particular metal contacts, $\mathrm{L}$ is distance between contacts and $\mathrm{W}$ is width of $\mathrm{n}$-InP between contacts (Fig. 3). $\mathrm{R}_{\mathrm{S}}$ and $\mathrm{R}_{\mathrm{C}}$ values are given in Table 1.

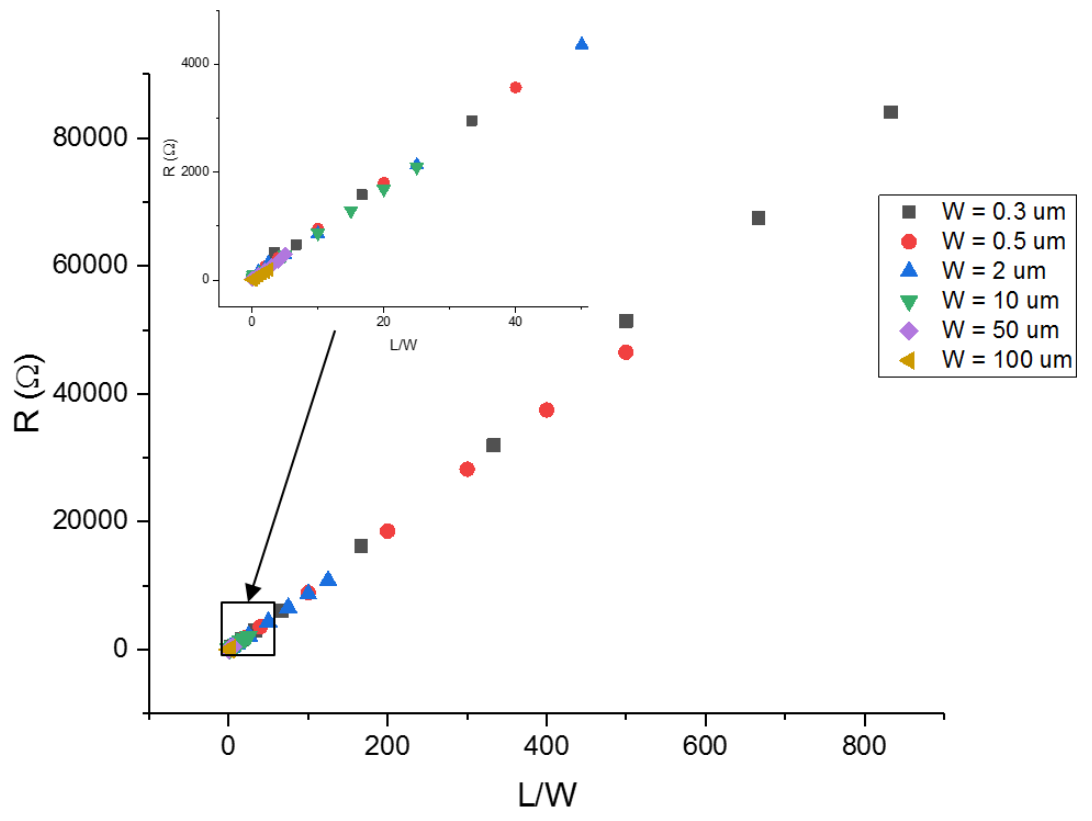

Figure 3. Transmission line measurement data for sample with $2 \cdot 10^{14} \mathrm{~cm}^{-2}$ implantation dose. 
Hall effect measurements were conducted for $\mathrm{n}$-InP using fabricated Hall bar structures in $-2-2 \mathrm{~T}$ magnetic field range, values of Hall carrier concentration $n_{\text {Hall }}$ and mobility $\mu_{\text {Hall }}$ are given in Table 1 .

Table 1. Electrical properties of Si ion implanted n-InP membrane.

\begin{tabular}{|c|c|c|}
\hline Total implantation dose, $\mathrm{cm}^{-2}$ & $2 \cdot 10^{13}$ & $2 \cdot 10^{14}$ \\
\hline $\mathrm{R}_{\mathrm{S}}, \Omega$ & $328 \pm 3$ & $75 \pm 1$ \\
\hline $\mathrm{R}_{\mathrm{C}}, \Omega$ & $12.9 \pm 1.2$ & $3.8 \pm 0.3$ \\
\hline $\mathrm{n}_{\text {Hall }}, \mathrm{cm}^{-3}$ & $3.3 \cdot 10^{17}$ & $2.9 \cdot 10^{18}$ \\
\hline Activation ratio, $\%$ & 49 & 44 \\
\hline$\mu_{\text {Hall }}, \frac{\mathrm{cm}^{2}}{\mathrm{~V} \cdot \mathrm{s}}$ & 2140 & 1040 \\
\hline
\end{tabular}

In case of implantation dose $2 \cdot 10^{14} \mathrm{~cm}^{-2}$, obtained carrier concentration is as high as $2.9 \cdot 10^{18} \mathrm{~cm}^{-3}$, however, with the penalty of decreased carrier mobility (compared with the sample with lower dose). Nevertheless, these results are promising for application in p-i-n structures in InP membrane. Even if activation annealing temperature is decreased from $800^{\circ} \mathrm{C}$ to some lower value (to avoid possible deterioration of the active material e.g. quantum wells), $\mathrm{n}$-InP resistance is expected to be usable.

\section{ZN THERMAL DIFFUSION}

Whereas ion implantation is an effective technique to create selective areas of n-type InP, for p-type InP it is hindered by low electrical activation ratios of p-type dopants. One alternative solution is to use $\mathrm{Zn}$ thermal diffusion in the MOVPE reactor with diethylzinc (DEZn) as $\mathrm{Zn}$ source ${ }^{12,13,14}$. This process takes place at $500-550^{\circ} \mathrm{C}$ under $\mathrm{AsH}_{3}$ atmosphere with $\mathrm{H}_{2}$ as a carrier gas. The diffusion is conducted in an Emcore Discovery D125 turbodisk system and in all the following experiments $\mathrm{AsH}_{3}$ flow is $175 \mathrm{sccm}$. Overall gas flow is around $28000 \mathrm{sccm}$ and chamber pressure is kept at $80 \mathrm{mbar} .100$ $\mathrm{nm}$ of plasma enhanced chemical vapor deposited (PECVD) $\mathrm{SiO}_{2}$ is used as a masking material. Before diffusion the sample is cleaned in concentrated sulfuric acid, followed by an annealing step at $650^{\circ} \mathrm{C}$ under $\mathrm{AsH}_{3}$. After diffusion rapid thermal annealing at $450^{\circ} \mathrm{C}$ for 5 minutes under $\mathrm{N}_{2}$ atmosphere is used to activate $\mathrm{Zn}$ dopants and clean sample from possible hydrogen-related impurities.

We started investigation of $\mathrm{Zn}$ diffusion with a test run on a 2" InP substrate with $50 \mathrm{~nm}$ of lattice-matched InGaAs on top without $\mathrm{SiO}_{2}$ mask to be able to get information about carrier concentration profile by using an electrochemical capacitance-voltage $(\mathrm{eCV})$ profiler. Diffusion was carried out at $505^{\circ} \mathrm{C}$ with molar flow ratio $[\mathrm{DEZn}]:\left[\mathrm{AsH}_{3}\right]=1: 5.5$ for 5 and 10 minutes. According to eCV measurements data (Fig. 4), hole concentration of $\sim 10^{18} \mathrm{~cm}^{-3} \mathrm{in} \mathrm{InP}$ can be achieved for $250 \mathrm{~nm}$ top layer for durations larger than 10 minutes.

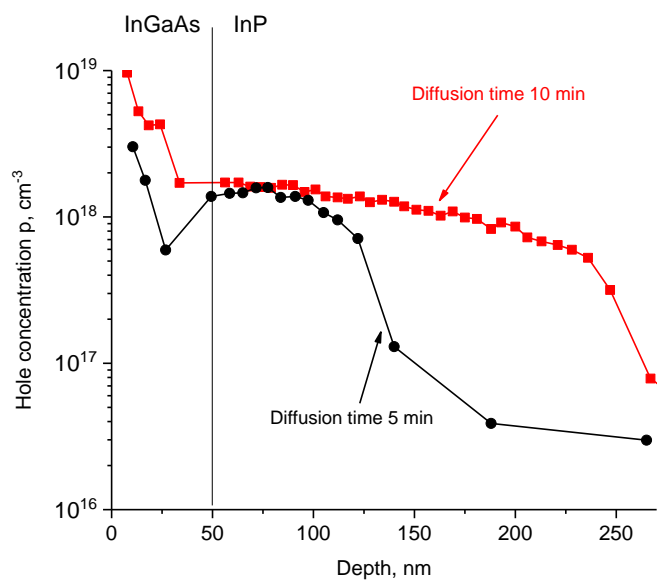

Figure 4. Hole concentration profiles in InGaAs/InP for different diffusion durations measured by eCV profiler. 
For samples with an InGaAs/InP membrane bonded to $\mathrm{SiO}_{2} / \mathrm{Si}$, eCV profiling is difficult due to the thick dielectric $\mathrm{SiO}_{2}$ layer. Transmission line measurements were carried out for the bonded $\mathrm{InGaAs} / \mathrm{InP} / \mathrm{SiO}_{2} / \mathrm{Si}$ sample, which was $\mathrm{Zn}$ diffused with the parameters mentioned above (diffusion duration was $30 \mathrm{~min}$ ). Surprisingly, sheet resistance of p-InP was found to be $3820 \Omega \square$ (Fig. 5), which, assuming mobility $200 \mathrm{~cm}^{2} / \mathrm{V} / \mathrm{s}$, corresponds to hole concentration being only $2.4 \cdot 10^{17} \mathrm{~cm}^{-3}$, almost one order of magnitude lower than for InP substrate based sample. This can be attributed to difference in $\mathrm{Zn}$ diffusion mechanism in InGaAs/InP membrane on $\mathrm{Si}$ and InP substrates, or it might be equipment-related.

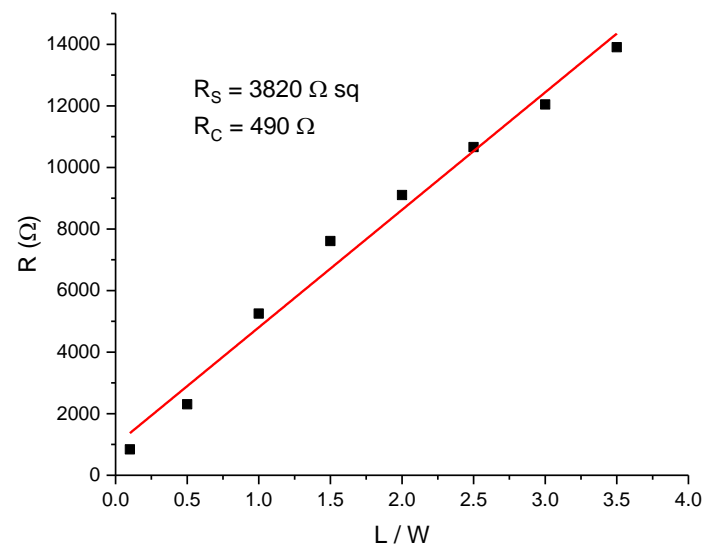

Figure 5. Transmission line measurements data for p-InP membrane on $\mathrm{SiO}_{2} / \mathrm{Si}$ ( $\mathrm{Zn}$ diffusion at $505^{\circ} \mathrm{C}, 30 \mathrm{~min}$ ).

Higher diffusion temperature was tried $\left(540^{\circ} \mathrm{C}\right)$, but it resulted in even less pronounced effect of $\mathrm{Zn}$ diffusion on not only the InP membrane, but also the InGaAs/InP membrane with InGaAs not being etched (remaining InGaAs would enhance possible effect of $\mathrm{Zn}$ diffusion). Estimated value of sheet resistance for $\mathrm{p}$-InGaAs/InP was increased by one order of magnitude (Fig. 6).
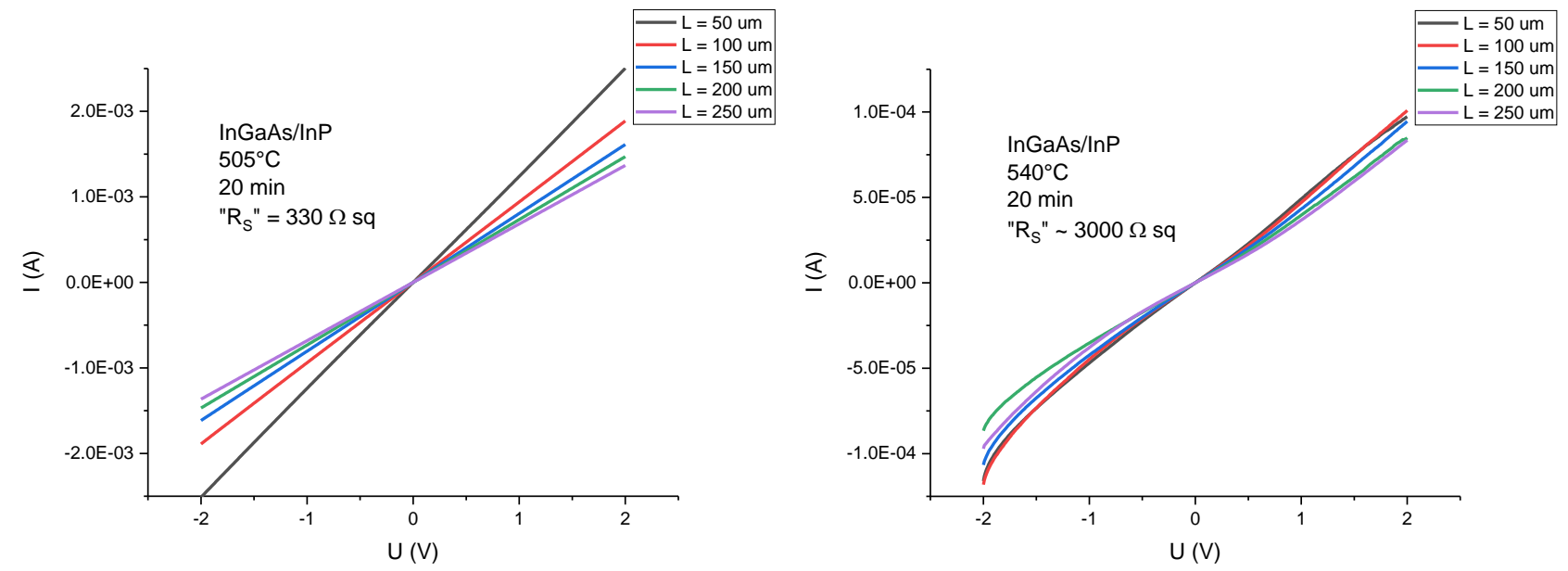

Figure 6. IV curves for p-InGaAs/InP membranes on $\mathrm{SiO}_{2} / \mathrm{Si}$. Left: $\mathrm{Zn}$ diffusion $\mathrm{T}=505^{\circ} \mathrm{C}$. Right: $\mathrm{T}=540^{\circ} \mathrm{C}$.

Eventually, DEZn molar flow was found to be of crucial importance for the zinc diffusion process. By adjusting different parameters, which have influence on DEZn molar flow, we achieved significant reduction in values of both pInGaAs/InP and p-InP sheet resistances (Fig. 7). 

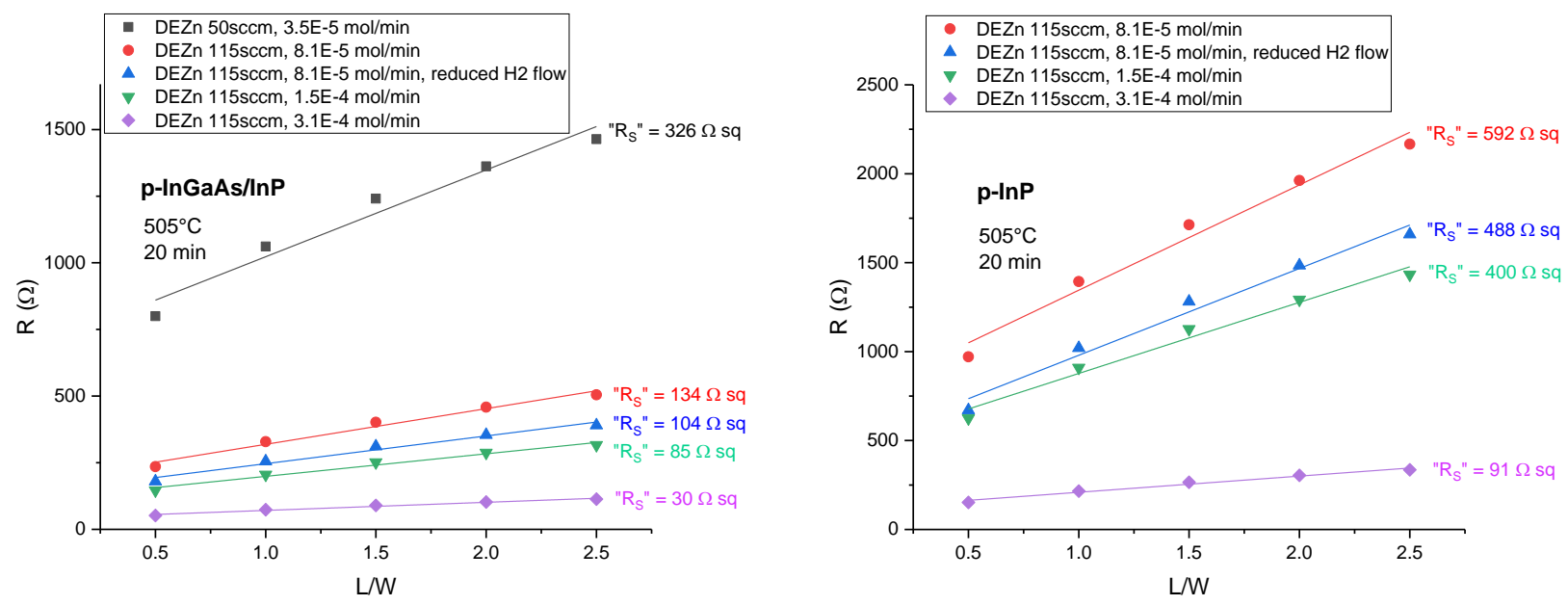

Figure 7. Transmission line measurements data for (left) p-InGaAs/InP and (right) p-InP membranes on $\mathrm{SiO}_{2} / \mathrm{Si}$ for different $\mathrm{DEZn}$ molar flows during $\mathrm{Zn}$ diffusion. Note: actual sheet resistance values are expected to be several times larger due to not ideal TLM test structures for this batch of samples.

For DEZn molar flow $3.1 \cdot 10^{-4} \mathrm{~mol} / \mathrm{min}$ (highest possible value using our DEZn bubbler), $505^{\circ} \mathrm{C}$ and diffusion duration of 20 minutes we obtained p-InP membrane with $\mathrm{R}_{\mathrm{S}}$ being only $690 \Omega$, which corresponds to hole concentration $1.3 \cdot 10^{18} \mathrm{~cm}^{-3}$ (Fig. 8).
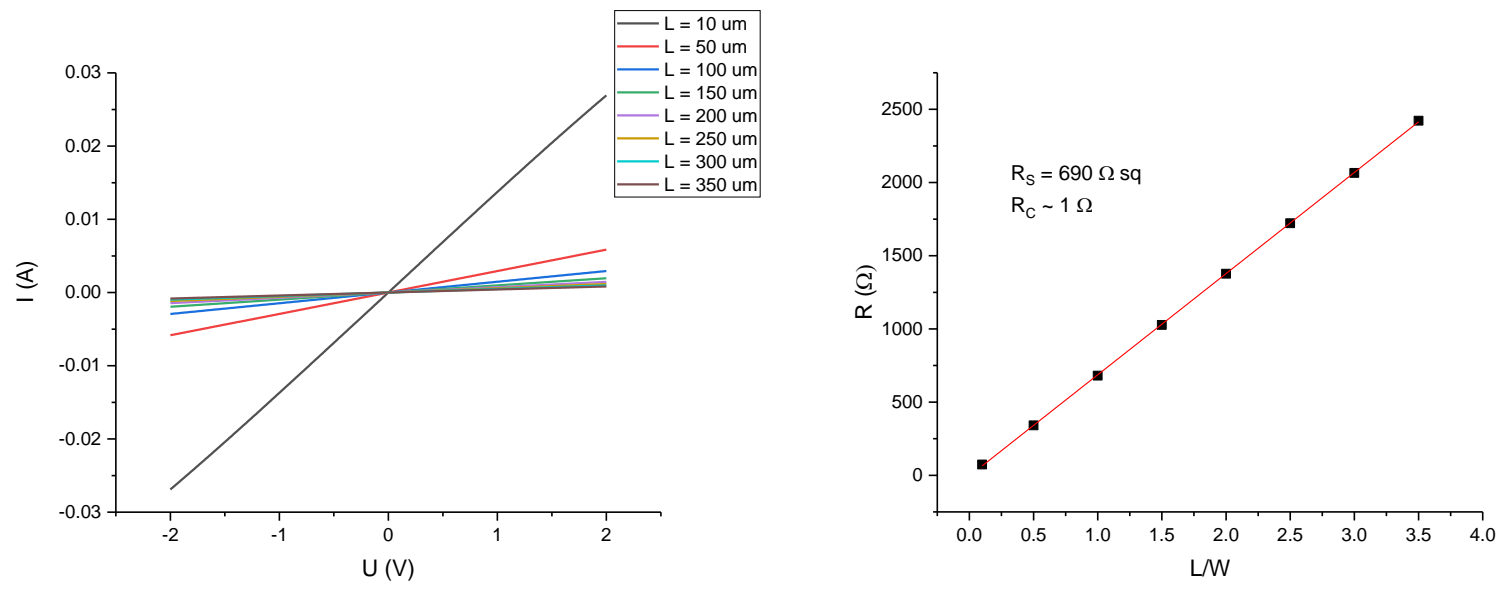

Figure 8. Left: IV curves for p-InP (Zn diffusion at $505^{\circ} \mathrm{C}, 20$ minutes, $\mathrm{DEZn}$ molar flow $3.1 \cdot 10^{-4} \mathrm{~mol} / \mathrm{min}$ ). Right: transmission line measurements data for the same sample.

In some cases we observe deterioration of initially perfect InGaAs surface after $\mathrm{Zn}$ diffusion. This deterioration is non-uniform and somewhat random. The same $\mathrm{SiO}_{2}$ mask openings can be deteriorated in quite different manner after $\mathrm{Zn}$ diffusion (Fig. 9). Moreover, this deterioration translates into underlying InP layer. Also there is a tendency of decrease in deterioration with increase of mask opening size, with smallest mask openings being most affected. 

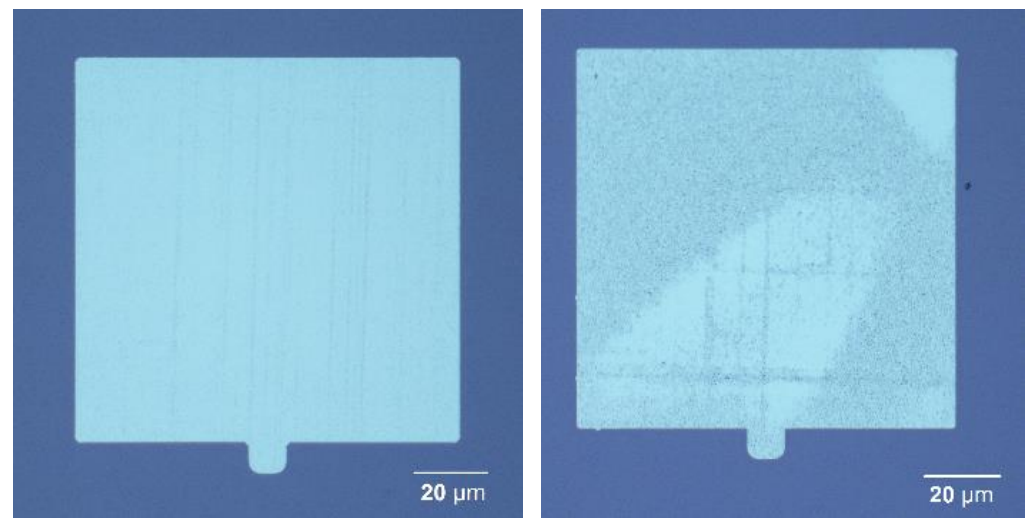

Figure 9. Optical microscope images of $\mathrm{SiO}_{2}$ mask openings after $\mathrm{Zn}$ diffusion.

With closer view this deterioration looks like trenches, which are aligned in approximately the same direction, as seen on atomic force microscopy (AFM) pictures (Fig. 10).

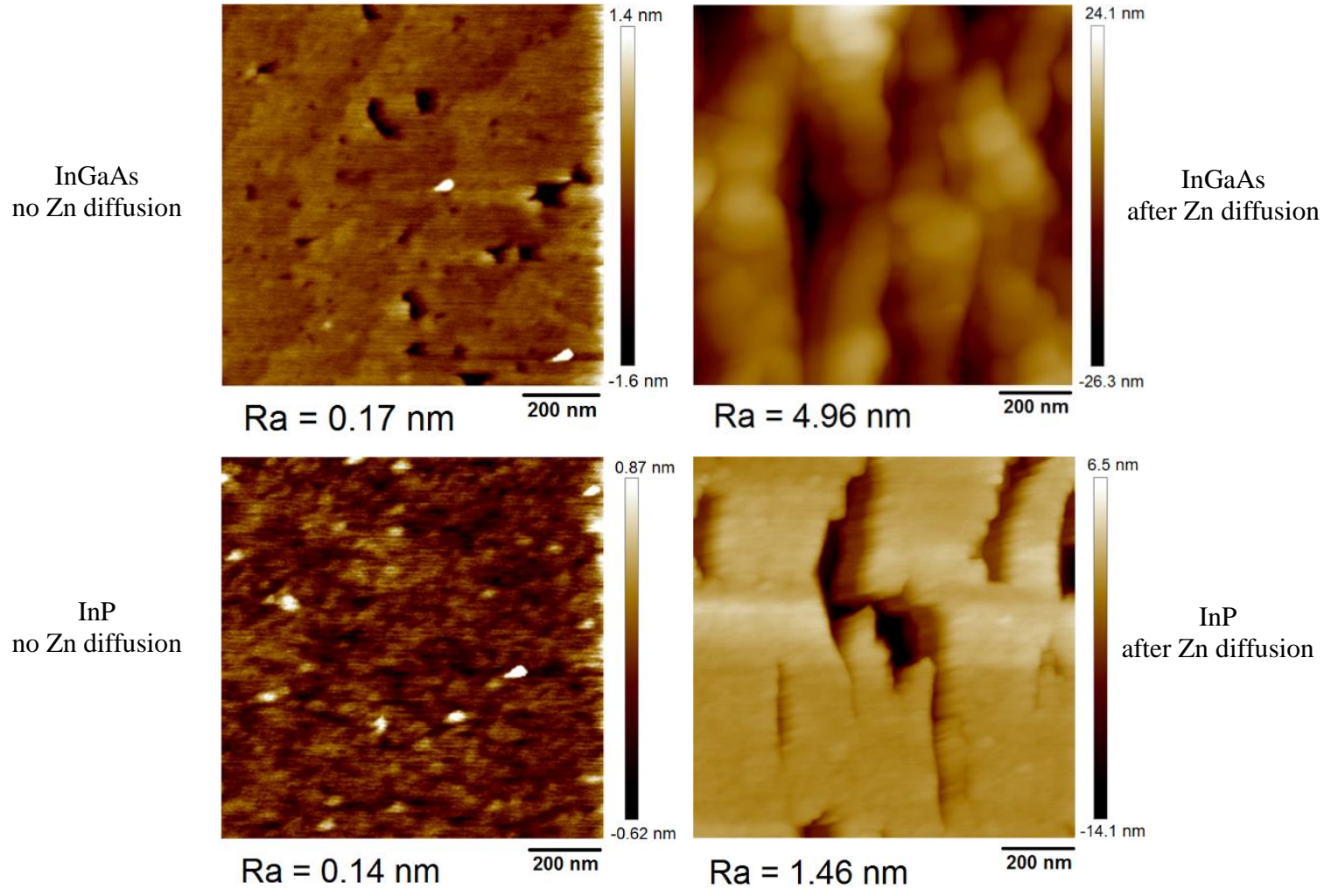

Figure 10. AFM images of InGaAs (top) and InP (bottom) surfaces without $\mathrm{Zn}$ diffusion (left) and after Zn diffusion (right).

No significant effect on electrical properties was observed due to deterioration of the surfaces. However, it could contribute to additional optical losses in the future device.

\section{P-I-N JUNCTION}

With use of abovementioned techniques for InP doping, it is possible to fabricate lateral p-i-n junction in InP membrane on $\mathrm{SiO}_{2} / \mathrm{Si}$ substrate. An initial result can be seen on Fig. 11. Characteristic curve and light response indicate successful fabrication of $\mathrm{p}-\mathrm{i}-\mathrm{n}$ junction. 


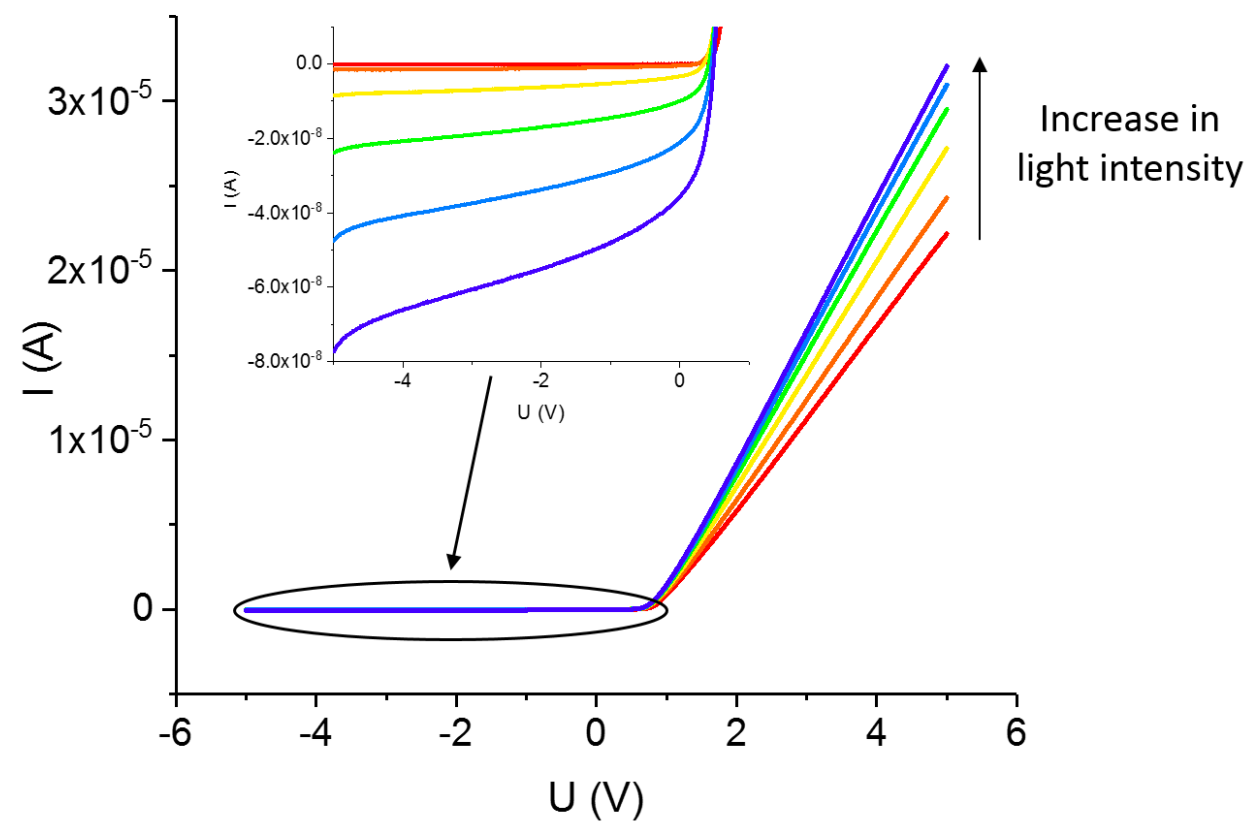

Figure 11. IV curves of p-i-n junction in InP membrane on $\mathrm{SiO}_{2} / \mathrm{Si}$ substrate under different illumination levels.

\section{CONCLUSION}

We have investigated and optimized $\mathrm{Zn}$ thermal diffusion in MOVPE reactor and $\mathrm{Si}$ ion implantation as efficient methods to fabricate lateral p-i-n junction in $\mathrm{InP}$ membrane bonded to $\mathrm{SiO}_{2} / \mathrm{Si}$ substrate. Carrier concentration levels of $1.3 \cdot 10^{18} \mathrm{~cm}^{-3}$ for $\mathrm{p}$-InP and $2.9 \cdot 10^{18} \mathrm{~cm}^{-3}$ for $\mathrm{n}$-InP are successfully demonstrated.

\section{ACKNOWLEDGEMENTS}

The authors acknowledge financial support from Villum Fonden via NATEC II (NAnophotonics for TErabit Communications) center.

\section{REFERENCES}

[1] Miller, D., "Device Requirements for Optical Interconnects to Silicon Chips", Proceedings of the IEEE 97(7), 11661185 (2009).

[2] Lupi, A., "Towards electrically pumped nanolasers for terabit communication", $\mathrm{PhD}$ thesis, Technical University of Denmark, Kgs. Lyngby (2015).

[3] Ellis, B., Sarmiento, T., Mayer, M, Zhang, B., Harris, J., Haller, E., and Vučković, J., "Electrically pumped photonic crystal nanocavity light sources using a laterally doped p-i-n junction”, Applied Physics Letters 96, 181103 (2010).

[4] Campenhout, J., Romeo, P., Thourhout, D., Seassal, C., Regreny, P., Cioccio, L., Fedeli, J-M., and Baets, R., "Design and Optimization of Electrically Injected InP-Based Microdisk Lasers Integrated on and Coupled to a SOI Waveguide Circuit", Journal of Lightwave Technology 26(1), 52-63 (2008).

[5] Shambat, G., Ellis, B., Petykiewicz, J., Mayer, M., Majumdar, A., Sarmiento, T., Harris, J., Haller, E., and Vučković, J., "Electrically driven photonic crystal nanocavity devices", IEEE Journal of selected topics in quantum electronics 18(6), 1700-1710 (2012).

[6] Takeda, K, Sato, T., Shinya, A., Nozaki, K., Kobayashi, W., Taniyama, H., Notomi, M., Hasebe, K., Kakitsuka, T., and Matsuo, S., "Few-fJ/bit data transmissions using directly modulated lambda-scale embedded active region photonic-crystal lasers", Nature Photonics 7, 569-575 (2013). 
[7] Sahoo, H. K., Ottaviano, L., Zheng, Y., Hansen, O., and Yvind, K., "Low temperature bonding of heterogeneous materials using $\mathrm{Al}_{2} \mathrm{O}_{3}$ as an intermediate layer," Journal of Vacuum Science \& Technology B, Nanotechnology and Microelectronics: Materials, Processing, Measurement, and Phenomena 36(1), 011202 (2017).

[8] Tsyganenko, A. A. and Mardilovich, P. P., "Structure of alumina surfaces", Journal of the Chemical Society, Faraday Transactions 92(23), 4843-4852 (1996).

[9] Ridgway, M.C., Kringhøj, P., and Johnson, C.M., "Ion implantation of group IV or VI elements for n-type doping of InP”, Nuclear Instruments and Methods in Physics Research B 96, 311-314 (1995).

[10] Lind, A.G., Gill, M.A., Hatem, C., and Jones, K.S., "Electrical activation of ion implanted Si in amorphous and crystalline $\mathrm{In}_{0.53} \mathrm{Ga}_{0.47}$ As", Nuclear Instruments and Methods in Physics Research B 337, 7-10 (2014).

[11] Wendler, E., Müller, P., Bachmann, T., and Wesch, W., "Defect production, annealing and electrical activation in $\mathrm{Si}^{+}$ implanted InP", Nuclear Instruments and Methods in Physics Research B 80/81, 711-715 (1993).

[12] Franke, D., Reier, F.W., and Grote N, "Post-growth Zn diffusion into InGaAs/InP in a LP-MOVPE reactor", Journal of Crystal Growth 195(1), 112-116 (1998).

[13] Haggren, T., Otnes, G., Mourão, R., Dagyte, V., Hultin, O., Lindelöw, F., Borgström, M, and Samuelson, L., "InP nanowire p-type doping via Zinc indiffusion”, Journal of Crystal Growth 451, 18-26 (2016).

[14] Acerbi, F., Tosi, A., and Zappa, F., "Growths and diffusions for InGaAs/InP single-photon avalanche diodes", Sensors and Actuators A 201, 207-213 (2013). 